\title{
Innovation and Exploration on Mode of Biology Graduate Students in Application-oriented Universities

\author{
Yuan Yuan ${ }^{1}$, Weidong Wang ${ }^{1}$, Yanhong Wang ${ }^{1}$, Mingcong Zhang $^{2}$, Shiqi $\mathrm{Ai}^{1}$, Mingyu $\mathrm{Cao}^{3}$, Di Wu ${ }^{4}$, Lei Yan $^{1}$, \\ Yamei Gao ${ }^{1}$, Shuang Zhang ${ }^{1}$, Sidan $\mathrm{Li}^{5^{*}}$
}

\author{
${ }^{1}$ Heilongjiang Provincial Key Laboratory of Environmental Microbiology and Recycling of Argo-Waste in Cold Region, College of Life Science and \\ Technology, Heilongjiang Bayi Agricultural University, Daqing 163319, China \\ ${ }^{2}$ College of Agriculture, Heilongjiang Bayi Agricultural University, Daqing 163319, China \\ ${ }^{3}$ College of Science, Heilongjiang Bayi Agricultural University, Daqing 163319, China \\ ${ }^{4}$ College of Engineering, Heilongjiang Bayi Agricultural University, Daqing 163319, China \\ ${ }^{5}$ Institute of New Rural Development, Heilongjiang Bayi Agricultural University, Daqing 163319, China
}

DOI: $10.36347 /$ sjebm.2020.v07i08.002

| Received: 30.07 .2020 | Accepted: 07.08.2020 | Published: 11.08.2020

*Corresponding author: Sidan Li

Abstract

Review Article

Based on the methods of postgraduate training at home and abroad, this paper analyzes the practical problems in the training of biology graduate students in application-oriented universities in China, such as the lack of hardware and software facilities and the lack of close connection between the training system and the market. Fusion development by building the open cultivation path, advancing with The Times to update the concept, precision lock training target system of thinking, put forward the classification of the training and precisely because of material teaching, strengthening teacher management, improve DaiTu actual effect and integration of academic resources, strengthening the construction of the platform, pay attention to the problems, propose solutions of biology graduate student training mode innovation, strive for applied undergraduate college biology graduate training quality, formation of operational stronger biology graduate cultivation model.

Keywords: Training mode; Biology graduate students; Application-oriented universities.

Copyright @ 2020: This is an open-access article distributed under the terms of the Creative Commons Attribution license which permits unrestricted use, distribution, and reproduction in any medium for non-commercial use (NonCommercial, or CC-BY-NC) provided the original author and source are credited.

\section{INTRODUCTION}

According to China's Ministry of Education, according to data from the statistical bulletin online nearly fifteen years of graduate student recruit students scale growth close to $151 \%$, in recent years, graduate student recruit students scale years remain at around $4 \%$, increase scale of postgraduate education has made great progress, the quality of graduate education. However, it showed a trend of decline, the deviated from the era of knowledge economy on talent cultivation target and demand, the reason such as the system and mechanism of the long form deep reason, social environment and the university's own factors. In January 2017 issued by the Ministry of Education, the State Council degree committee of the degree and graduate education development "much starker choicesand graver consequences-in planning" explicitly put forward: "strengthen the training unit quality assurance subject status and main body responsibility, enhance the quality consciousness, establish is consistent with the educational objectives and positioning the unit quality standards, achieve high level of graduate education". As the first responsible unit for postgraduate quality assurance, training units undertake the task of providing high-level intellectual support for the society. Highquality postgraduate training is directly related to social development. How to guarantee the quality of postgraduate education has become an important issue to be studied and solved.

\section{Analysis of research status at home and abroad Research Abroad}

Since the $1960 \mathrm{~s}$, the economic and social development of science and technology and national policy factors comprehensive influence, the nations of the world into scale rapid expansion, this lead to a graduate student in education of postgraduate students groups and their needs diversification. The graduate cultivation model also increases diversified under this background, the postgraduate education quality, improve the efficiency of postgraduate education, became the various countries' important policy issues of common concern to total quality management (TQM) is also in the last century 60s by America's general electric's evan feigenbaum of modern quality management thought, refers to an organization take the 
quality as the center, through the adoption of modern production and management technology, on the basis of full participation, affecting the quality of the whole process of a comprehensive system of management and other factors, to let the consumer satisfaction and all members of the organization and social benefit of long term success management approach to its basic connotation can brief statements to keep consumers satisfied with the participation of continuous quality improvement and management $[1,2]$.

According to the fact that its core characteristics can be summarized as three, namely a comprehensive quality management and participation of the whole process of management management TQM. Since 60 s produce, in Japan and Europe and the United States field of enterprise management has been widely promotion and application, has a good benefit, in the $80 \mathrm{~s}$, the higher education quality assurance present crisis, the European and American countries developed countries represented by the United States and France set out to improve the quality of talent cultivation, the first to apply TQM ideology to the cultivation of talents in the quality control and evaluation into the $1990 \mathrm{~s}$, the British beautyAustralia and other countries gradually shift quality evaluation center of gravity by colleges to students, from the uneven distribution of resources to the resources use efficiency, and students to study the effect of the transfer, trying to build internal education in colleges and universities take the student as the teaching quality guarantee system, strengthening method technology research at the same time, the development of students' learning effect evaluation tools, training process importance as well as the student main body status of the highlights in western countries are introducing TQM thought and practice, effective, only in the United States[3-5]. For example, with characteristics of TQM thought extremely practice of ISO9000Series quality certification system is effectively applied to many universities talents cultivation of overview of foreign graduate students in the quality control and evaluation of the quality guarantee system construction development, pay more attention to the subject status of graduate students in the training process, the quality of graduate students in the process of training experience and feedback into the security system is the European and American postgraduate education common practices in developed countries for more than 20 years, western countries the success of TQM practices show that the proposed is feasible for ensure the quality of talent cultivation in colleges and universities, the basic connotation and core characteristics also conforms to ensure quality of talent cultivation in colleges and universities and the road of connotative development under the guidance of the real need.

\section{Domestic Research Status}

China's higher education sector has begun to pay attention to and gradually promote the construction of higher education quality assurance for student participation, but the existing research and practice mainly focus on undergraduate education, while the lack of sufficient attention to student participation in graduate education. From 2005 to 2020, the enrollment scale of graduate students in Universities and colleges in China has been continuously expanding, increasing from 364,800 in 2005 to 916,500 in 2020 , with an increase of $151 \%$. The continuous expansion of the scale of graduate students in China is bound to bring about the mismatch between quality and quantity, which has become a hot issue that many domestic scholars have begun to discuss. $\mathrm{Hu}$ Rong et al. proposed that the factors affecting the training quality of graduate students can be analyzed from both subjective and objective aspects. Among them, subjective factors mainly refer to the quality of students, while objective factors include teaching resources and training process. Liao Wenwu et al. put forward countermeasures to improve the quality of postgraduate training from the aspects of educational quality guarantee mechanism, enrollment system, tutor team, self-assessment and educational funds. Gao Yang studied various factors that influence the quality of postgraduate education from both internal and external perspectives, and proposed that the internal factors mainly include the quality of students, the guidance of tutors, and the training conditions, while the external factors refer to the influence of the government and society on the quality of postgraduate education. Wang Lili identified the key factors that affect the quality of graduate students from different aspects, such as graduate students, teachers, schools and society, from the micro perspective. Hu Chunping et al. put forward countermeasures to improve the supervision system, the coordinated development of industry, education and research, and the optimization of management mode, which are conducive to the scientific training of graduate students from different aspects of the state, society and school [6-8].

\section{Problems in postgraduate training in application- oriented universities}

The hardware and software facilities and conditions of postgraduate training still need to be improved. In national degree and graduate education under the background of rapid development, applied undergraduate colleges and universities in response, carry out and implement the Ministry of Education of the national medium and long-term education reform and development plan outline (2010-2020) put forward "comprehensively improve the quality of higher education" of the spirit and fully implement the Ministry of Education "about comprehensive several opinions on improving the quality of higher education, before the real need of on degree and postgraduate education has been fully development and progress, 
through their adjustment, many schools has also formed a multi-disciplinary degree authorization system, and its degree authorization type and diversified cultivation standard gradually appear. With the establishment and development of China Academic Degrees and Graduate Education Academic Degrees Working Committee, many application-oriented universities have also changed their ideas, gradually changing from quantitative growth to quality-oriented development [912]. However, with the rapid development of degree and graduate education in application-oriented universities, there are also some perplexities and problems. The main problems are that the source of students is still severe, the subject resources and level are insufficient, the teaching environment is not innovative enough, the soft environment of graduate education is insufficient, and the guarantee mechanism of long-term operation needs to be established and developed.

The cultivation system is not closely connected with the market development. With the increasing number of graduate students, the employment pressure has become increasingly prominent; especially the life science graduate students are facing unprecedented challenges. Despite the deeply for life science research, but, the study of life science in China starts late, the corresponding molecular breeding, biological engineering, medical and health related biological industry is relatively lag, besides some small amount of scientific research institutes, mainly large and medium-sized enterprises jobs given main group significantly weaker, no support by huge life sciences industry system, the graduate student's employment channels is extremely narrow. And postgraduate training mode and teaching mode and the reality demand there is a certain degree of dislocation, part of the graduate student scientific research task LiTi biased or old site, keep pace with reality technology development, practicality is not strong, or graduate teaching exists old book content, single teaching mode, teaching practice less phenomenon. The above problems aggravate the employment difficulties of graduate students majoring in life science and make them feel confused about their ideal and future.

\section{General idea of training biology graduate students in application-oriented universities}

Open and integrated development pays attention to the cultivation path. At present, environmental pollution, lack of food, shortage of resources and human health has become major problems threatening social development and will become more prominent with social and economic development. To solve these problems fundamentally, we must rely on the development of life science. Since the 20th century, with the development of mathematics, physics, chemistry and other disciplines, life science has gradually become an important factor affecting social development and an important dependence on improving people's quality of life. Science and technology are the primary productive forces, and the key to scientific development lies in personnel training. Therefore, training high quality graduate students is a long-term plan to do a good job in talent reserve. The biology major in application-oriented universities has the attributes of interdisciplinary and integration, and the cultivation of innovative and entrepreneurial talents across disciplines and disciplines is of special significance. Under the new situation, we should seek truth from facts according to the actual circumstances of the current applied undergraduate college biology graduate student, must respond to the "Double Gen" strategy, formulate feasible training plan, "production, teaching, learning and research", introducing the ideas of total quality management (TQM) university graduate training quality assurance practice, the selection and use of effective strategies for promoting cross disciplines and specialties, effectively improve the quality of applied undergraduate colleges and universities graduate education in biology[13].

\section{Keep pace with The Times innovation training concept}

Combining with the characteristics of biological disciplines disciplines, as well as biological kind of emerging industrial market demand, based on the perspective of TQM, biology graduate education for applied undergraduate colleges and universities in the process of quality assurance to make a series of exploration and improvement, effectively improve the applied undergraduate college biology graduate student's overall quality and level, use of regional features, entrepreneurial innovation fusion, in order to adapt to our country for high level in the biological sciences "Double Type" talented person's demand, transformation of better serve the local economic development, provide powerful talent intelligence support for constructing a creative country, has a broad application prospect. Through teaching, management, and personnel training work for a long time in a line of teachers engaged in teaching reform and teaching research, to guide the graduate students innovative undertaking training project, and related innovative talents in different schools, outstanding engineers training mode of cooperative study, the personnel training mode and quality guarantee system at home and abroad understanding, can be accumulated a certain amount of research results, as a graduate student training mode innovation study to lay a good foundation. For example, there are 44 full-time faculty members, including 7 doctoral supervisors, 36 master supervisors and 2 off-campus part-time supervisors.

\section{System analysis of the situation to lock research objectives}

Comprehensive analysis of the applied undergraduate colleges and universities graduate biological current insufficiency of training system and 
teaching content, combined with local economic transformation development and cross-border integration of new features of the demand response to the development of China's manufacturing 2025 requirements, the use of interdisciplinary, cross major, inter-departmental coordination method, cross-industry depth cooperation, to explore the effective strategy of improve the quality of graduate education in biology, in ensuring that applied undergraduate college graduate majored in biological education benefit, will start for whole biological disciplines "Double Type" talent training quality strategy to provide important reference [14]. At the same time, it can also drive the same major in China to start or build cross-disciplines to improve the quality of graduate education to provide an important reference value; In the perspective of total quality management, adhere to the principle of "Wisdom Made in China", "Double Gen" spirit as the core, to strengthen biology graduate students innovative entrepreneurial skills as the goal, from the students themselves, the three dimensions, the platform construction of the contingent of tutors, proposed conforms to the applied undergraduate colleges and universities graduate education in the biology of highquality quality assurance strategy, to adapt to the market for high level biology class "double type" talented person demand. The cumulative achievements of the school in the past 5 years are shown in Fig.1.

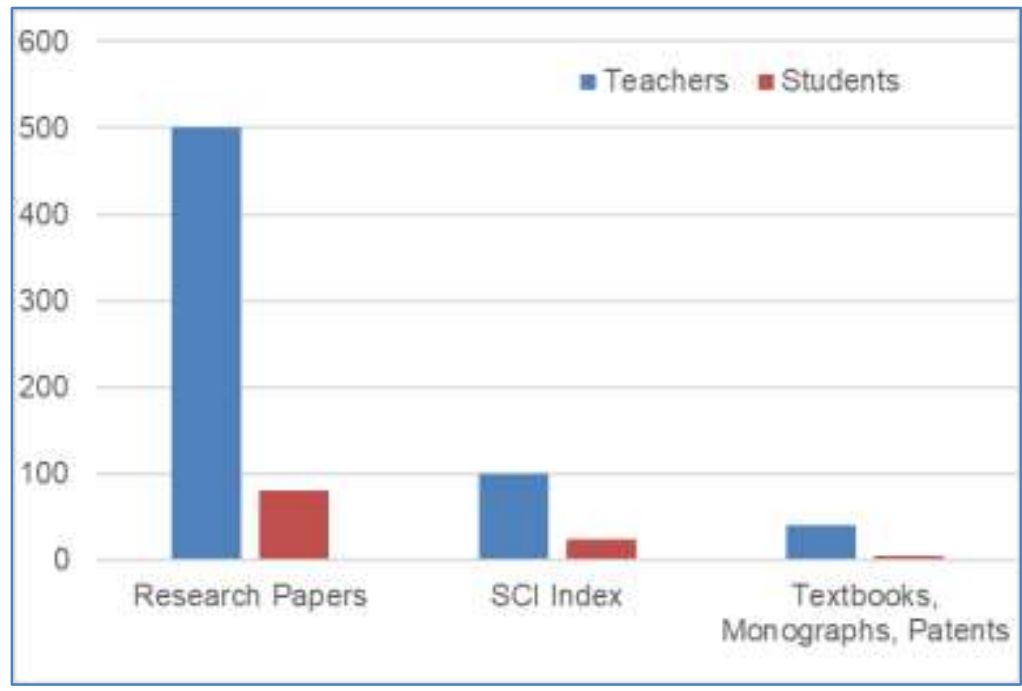

Fig-1: The cumulative achievements of the school in the past 5 years

\section{Exploration and Innovation of training Mode of biology graduate students in application-oriented universities}

Do a good job of training students in different categories and teaching them precisely according to their qualifications.

Based on THE MODE of PCI (Plan + Personality, Collaboration + Communication, Inheritance + Innovation), a higher standard than the school has been set in terms of subject application, article publication and participation in activities of the team. On the basis of the original tutorial system, according to the characteristics of the students according to their aptitude of individualized education and social demand, fully considering the synchronous cultivating students' professional and moral accomplishment, also should be to further improve the incentive mechanism of graduate student education and talent cultivation model, carry out equal dialogue and communication between graduate students and more subjects and the exchange, provides a better academic environment and growth environment, cultivating graduate students self-learning and self-protection of autonomy and independence, fully mobilize the enthusiasm and initiative of graduate students for scientific and technological innovation, encourage and support to participate in high level scientific research projects and high level papers published. Furthermore, PDCA quality loop is introduced to conduct real-time evaluation of the entire training process, which is conducive to the implementation of quality management in every detail of postgraduate training and to ensure the professional level of students.

\section{Strengthen the management of mentors and improve the effectiveness of apprentices}

We will strictly control the selection of tutors, constantly improve the tutor assessment system, combine rewards and punishment measures, hold tutor meetings regularly, train and scientifically plan the tutor team, employ industry experts as tutors, and form a double tutor team inside and outside the school. Secondly, the mentoring way should be reformed to realize the organizational operation under the mentor team mode, increase the communication among various disciplines, and even carry out interdisciplinary cooperation, so as to provide students with the opportunity to communicate with different tutors and promote the all-round development of graduate students. Thirdly, we should advocate teaching students in accordance with their aptitude. Mentor from the 
reality of the students, strengthen the understanding of the differences between each of the students, guide the students' personality development, encouraging its development thinking, continuously introducing the problem oriented teaching method (Problem-based Learning, PBL), Seminar teaching mode, create a
"Lesson" environment, more middle school students' active participation in class, encourage teachers to bilingual or the whole English teaching, improve teaching quality and efficiency, establishing grant system, strengthen students' scientific research power (Fig.2 and Fig. 3).

\begin{tabular}{|c|c|c|c|c|}
\hline 颀 & 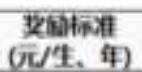 & \multicolumn{2}{|l|}{ 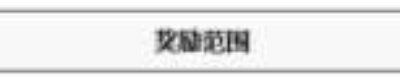 } & 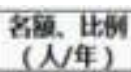 \\
\hline 国安平台 & 20000 & \multicolumn{2}{|c|}{ 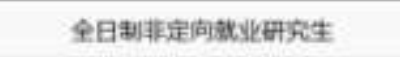 } & 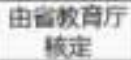 \\
\hline 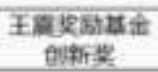 & 2000 & \multicolumn{2}{|c|}{ 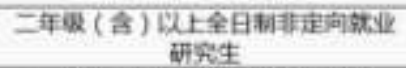 } & ent \\
\hline \multirow{3}{*}{ 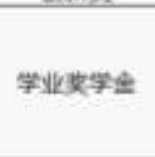 } & 8000 & 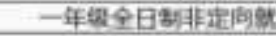 & k研究生 & $100 \%$ \\
\hline & 11000 & \multirow{2}{*}{\multicolumn{2}{|c|}{ 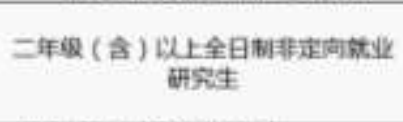 }} & 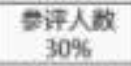 \\
\hline & 9000 & & & $\begin{array}{c}\text { Tif人e } \\
50 \%\end{array}$ \\
\hline \multirow{5}{*}{ 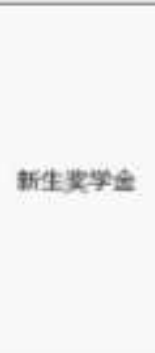 } & 10000 & \multirow{2}{*}{ 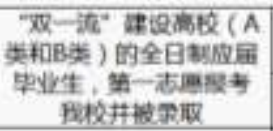 } & 要术学位 & \multirow{2}{*}{$100 \%$} \\
\hline & 8000 & & 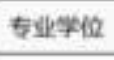 & \\
\hline & 6000 & \multirow{2}{*}{ 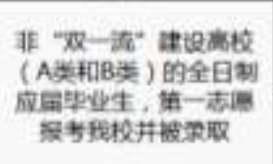 } & 学术穿位 & \multirow{2}{*}{ 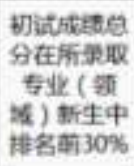 } \\
\hline & 5000 & & 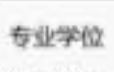 & \\
\hline & $\frac{8000}{6000}$ & 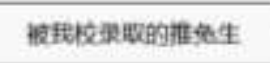 & $7 x+215$ & $100 \%$ \\
\hline
\end{tabular}

Fig-2 Scholarship system in Chinese

\begin{tabular}{|c|c|c|c|c|}
\hline 춧묘 & 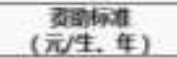 & 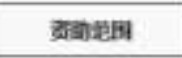 & 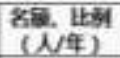 & 鲡注 \\
\hline Ixsin 7 k & 6000 & 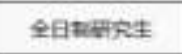 & $100 \%$ & 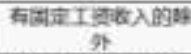 \\
\hline \multirow{2}{*}{ 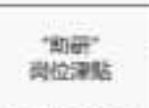 } & 1000 & \multirow{2}{*}{ 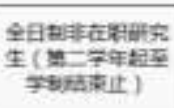 } & \multirow{2}{*}{$100 \%$} & 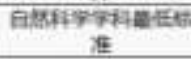 \\
\hline & 500 & & & 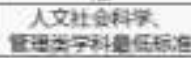 \\
\hline 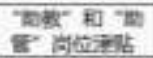 & 8000 & 이 & 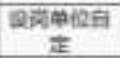 & 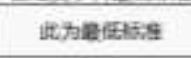 \\
\hline 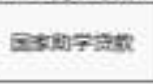 & 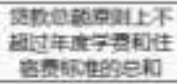 & 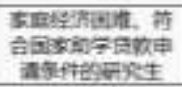 & Tरस & \\
\hline
\end{tabular}

Fig-3: Financial aid system in Chinese

\section{Integrate the resources of the school and strengthen the platform construction}

The management of graduate students by the competent departments of schools and colleges provides guarantee for the improvement of training quality. Management and quality are interdependent and inseparable. First of all, the graduate student academic exchange platform, to promote scientific innovation ability to be able to research, innovation as basic requirement, organization of famous professors and industry experts to carry out frontier theory, engineering and technical lectures, seminar for graduate student academic BBS, and combining with PCI model, expanding foreign exchange as the main line, form a good academic atmosphere, inspire students' consciousness of independent innovation and pioneering spirit. Second, create conditions for the graduate students to carry out the scientific research practice, optimizing the allocation of resources, through the national platform and key laboratory, conducting production-teaching-research combination, of mentor intercollegiate exchange to improve their ability, strengthen the construction of the platform, training of users, with convenient modern communication technology between teachers and students and schools, established between timely and smooth communication and feedback mechanism, establishment graduate student self-management and service platform, set up the employment practice base and graduate workstation [15].

Focus on problem orientation and propose solutions

Aiming at the problem of poor innovation of teaching environment, improve teaching quality and efficiency; Aiming at the problem of insufficient subject resources and level, excellent teaching materials, teaching reference materials and auxiliary materials at home and abroad are selected, and the network core course teaching platform is used to share high-level resources to build the core curriculum group of biology. For postgraduate education to the problem of shortage of soft environment, through integrating the resource of schools, and diversified platform construction, set up diversified academic exchange platform of graduate students and combining PCI model, expanding foreign exchange as the main line, 
Yuan Yuan et al., Sch J Econ Bus Manag, August, 2020; 7(8): 233-239

form a good academic atmosphere, fully mobilize the enthusiasm and initiative of graduate students for scientific and technological innovation, constantly improve the quality of graduate education, at the same time create a graduate student self-management and service platform, set up the employment practice base and graduate workstation; In view of the lack of practical teaching experience in the process of graduate student training, this paper proposes countermeasures to improve the quality of graduate student training from the three dimensions of students, tutors and platforms through investigation and research, combining closely with the industrial structure and regional demand, and taking the revision of school training program as an opportunity.

\section{CONCLUSION}

The quality of personnel training is the most important lifeline of education and the quality of graduate education is the fundamental guarantee for the sustainable development of education. The most important prerequisite for building a quality assurance system for graduate education that meets the needs of The Times is to carry out all educational activities around the theory of quality, that is to say, to firmly establish the correct quality view of graduate education is the primary prerequisite for the current graduate education work. Application-oriented universities should take a number of measures to promote the cultivation of innovative talents, strengthen the construction of emerging disciplines such as information, biology and nano science in the discipline system construction, carry out interdisciplinary research, and pay attention to the core scientific problems to be solved in industrial upgrading and structural adjustment. Facing the new situation and new changes, through analyzing the research situation of graduate education in colleges and universities, inductive deduce patterns and methods of the graduate student education both at home and abroad, to be effective for implementation method and the effective path to improve the quality of graduate education, put forward in accordance with local university graduate training quality strategy, effectively improve the quality of graduate education in biology, to adapt to the new era of industry transformation and the regional economic development needs.

\section{ACKNOWLEDGEMENT}

This work was supported by Research Project on Teaching Reform of Degree and Postgraduate Education in Heilongjiang Bayi Agricultural University (YJG201802); Youth Special Project in the 13th FiveYear Plan of Education Science in Heilongjiang Province (GJD1318025); Key Project in the 13th FiveYear Plan of Education Science in Heilongjiang Province (GJB1320232); General Research Project on Teaching Reform of Higher Education in Heilongjiang Province (SJGY20190482); Teaching Research Project of Heilongjiang Bayi Agricultural University (NDJY1638).

\section{REFERENCE}

1. Jin Wei. Evaluation of postgraduate Education Quality centered on "Learning" -- Based on comparative Analysis of Britain, The United States and Australia [J]. Exploration of Higher Education. 2017, (3): 86-90.

2. Chen Shihui, Zhang Lianxu. College students' innovative undertaking education international pattern, the experience and draw lessons from, based on the comparison of the United States, Germany, Japan and other countries [J]. Journal of continuing education research. 2018, (1): 115-120.

3. Huang Ying, Ma Xiang, Ma Yitong. PCI model combining PDCA cycle quality management improve the quality of medical graduate student academic culture $[\mathrm{J}]$. Journal of medical education management. 2018, 4(1): 44-47.

4. Zhong Jianfeng, Wang Hui, Chen Da. Construction of graduate student Training quality assurance system from the perspective of system theory [J]. Science and Education Wenhui (Mid-Jun.). 2018, 422(5): 1-3, 26.

5. Pece A M, Simona O E O, Salisteanu F. Innovation and Economic Growth: An Empirical Analysis for CEE Countries [J]. Procedia Economics \& Finance. 2015, 26:461-467.

6. Li Hongwei, Ren Yingying, Tao Min. Analysis of key Factors influencing the Quality of Postgraduate Training in China based on DEMATEL Method $[\mathrm{J}]$. Science and Technology Innovation Guide. 2017, 14(17): 209-212.

7. Fan xinmin, gao zhihuai. The path of cross-border integration of talent training and innovation and entrepreneurship education proposed by One Belt And One Road [J]. Journal of hebei normal university (education science edition). 2018, 20(2):119-121.

8. Liu Bo. Quality Assurance of Graduate Student Training based on Total Quality Management [J]. Innovation and Entrepreneurship Education. 2015, 6(6):149-152.

9. Fan Xinmin, Gao zhihuai. Path of cross-border integration of talent training and innovation and entrepreneurship education under the "One Belt And One Road" initiative [J]. Journal of hebei normal university (education science edition). 2018, 20(2):119-121.

10. Shao Defu, Li Chunjiang, Ma Xiaojun. Research on training Mode of Innovation and Entrepreneurship Ability of New Engineering Talents in Local Universities [J]. Science and Technology Entrepreneurship Monthly. 2017, 30(19): 62-64.

11. Li Bin, Zhai Xuefeng, Li Decai. Strategy Research on talent Training Mode Reform in Higher Agriculture and Forestry Colleges [J]. China Forestry Education. 2017, 35(3):28-30. 
12. Zhang Shaoli, Zheng Xiaoqi. Innovative Application of TOTAL Quality Management in interdisciplinary Postgraduate Training Mechanism [J]. Modern Education Management. 2018, (5):123-128.

13. Li Jinshan, Qi Jing, Fu Jun. Analysis report on the Employment status of Biology Postgraduates in Agricultural Colleges and Universities -- A Case study of Huazhong Agricultural University [J]. Hebei Vocational Education. 2010, 6(3):165-167.

14. Song Yuwei. Life sciences graduate training quality present situation analysis and countermeasure research $[\mathrm{J}]$. Journal of quality education in the west and. 2017, 3(15): 4-5.

15. $\mathrm{Xu}$ Bo, LI Yeqing, ZHOU Tong. The biological professional degree postgraduate quality guarantees system to explore $[\mathrm{J}]$. Journal of university of education. 2017, (1):163-164.

16. Xie Zhiju, Zhu Shaohao. Discussion on quality Assurance mechanism of Graduate Education from the perspective of multi-center Governance Theory [J]. Modern Education Management. 2017, (4):102-107. 